\title{
El espacio público entre las normas y la informalidad: diálogo de dos ciudades, San José (Costa Rica) y Bogotá (Colombia)
}

Recibido: 2 de mayo 2016

Revisado: 15 de mayo 2016

Aprobado: 23 de setiembre 2016

Rosibel Víquez Abarca

Costarricense. Doctora en Geografía Humana de la Escuela de Geografía, Política y Sociología de la Universidad de Newcastle upon Tyne, Reino Unido. Magíster Scientae en Diseño Urbano de la Universidad de Costa Rica. Investigadora del Programa

PROGLOCDE del CICDE-UNED.

Participa en redes

interdisciplinarias sobre temas relacionados con desarrollo

territorial, agua y educación superior; este último desde la vinculación universidad-territorio.

También es parte de la Agenda

CICDE por el Agua, iniciativa de

investigación interesada por la integración de la investigación y la incidencia en el tema de

organización por la defensa del agua en Costa Rica. Correo electrónico: rviquez@uned.ac.cr

Jaime Hernández García

Colombiano. Doctor en

Arquitectura, Urbanismo y Paisajismo de la Universidad de Newcastle Upon Tyne, Reino Unido.

Profesor en la Facultad de

Arquitectura y Diseño, Pontificia

Universidad Javeriana, Colombia. En el año 2012 obtuvo en México el "Premio Iberoamericano de Tesis de Investigación sobre Vivienda y Espacio Urbano Sustentable". Entre sus publicaciones recientes se encuentran: "Underlying Language and Meaning of Informality";

"Sustainability Citizenship: Lessons and Challenges from Informal Settlements"; y "Habitat Popular, un Modo Alternativo de Produccion de Espacio para America Latina?" Correo electrónico: hernandez.j@javeriana.edu.co
Resumen: El presente artículo discute el uso y la apropiación del espacio público desde el diálogo de dos investigaciones, de distintos contextos y desde distintos actores para mostrar la diversidad de enfoques con las potencialidades y las dificultades de los mismos en San José y Bogotá. Por una parte, el uso que le dan los jóvenes a dichos espacios en el centro de San José en contravía de las normas establecidas dentro de las "ciudades de manual" y, por otra parte, el uso que le dan los habitantes de los barrios populares periféricos en Bogotá desde la informalidad. Estas dos aproximaciones identifican relaciones que se entretejen entre el espacio y los habitantes y entre los distintos actores, incluyendo el Estado, a partir de las cuales se aprecian lecciones de la regulación y la informalidad que bien pudieran tenerse en cuenta en el estudio y la proyección de nuestras ciudades latinoamericanas. Las lecciones que también devienen en conflictos e intrincadas relaciones de poder.

Palabras clave: espacio público; ciudad central; planeación formal e informal; barrios populares asentamientos informales; jóvenes; conflicto; poder.

\section{Public Space, between Regulations and Informality: A Tale of Two Cities, San José (Costa Rica) and Bogotá (Colombia)}

Abstract: This paper discusses the use and appropriation of public space deriving from the dialogue between two research projects which come from different contexts and had different social actors, this to show the diversity of approaches, their potential and also their weaknesses both in San Jose and Bogota. On one hand, the way young people in San Jose city centre use such spaces against a "City Guide" approach, and on the other hand, the use which inhabitants of working-class neighborhoods in Bogotá give to their public spaces. Both research projects identify relationships weaved between space and its inhabitants, and between the inhabitants themselves and the different social actors, including The State, from which there are lessons on regulations and informality that could be part of the study or even the projection of our Latin American cities. These lessons can also end up in conflicts and intricate power-relations.

Key words: public space; central city; formal and informal urban planning; informal settlements; young users; conflict; power. 


\section{Introducción}

La construcción social del espacio es la transformación real del mismo [sic] — a través de intercambios sociales, recuerdos, imágenes y uso cotidiano del entorno material- en escenas y acciones que transmiten un significado simbólico (Low 2000, p.861-862).

El espacio público le da forma y representación a la vida colectiva en la ciudad (Carrión 2007) y es contenedor de significado político y poder simbólico (Madanipour 1999; Rosenthal 2000; Hernández-García 2012). Mediante el proceso perceptual, dicho espacio se diseña con la superposición de la forma, la apariencia y la imagen (Víquez, 2006). Las interacciones humanas con los espacios públicos presentan, al menos, dos aspectos siempre entrelazados: el funcional y el simbólico; el primero entendido como el uso físico y cotidiano del espacio, y el segundo como la interacción experiencial y de representación. Así como estos intercambios con el lugar puede transformarlo, así también los tipos de uso pueden transformar las relaciones sociales y generar distintos niveles de pertenencia al lugar y apropiación del mismo. No obstante, "vivimos en ciudades cada vez más divididas, fragmentadas y proclives al conflicto" (Harvey 2013, 35); conflicto que se expresa sobre todo en complicadas relaciones de poder.

En los espacios públicos abiertos de los centros urbanos, las personas usan los espacios siguiendo la jerarquización definida por la planificación de la ciudad (Víquez 2006; Víquez y Leandro 2006) atendiendo a la estética de la ciudad o a los eventos prediseñados como pasacalles, festivales y ferias en las que se involucra a los participantes, invitándoles a ser parte del contexto urbano. Por contraste con lo anterior, en los barrios populares bogotanos, las actividades en espacios públicos están relacionadas con las prácticas sociales y culturales que se llevan a cabo siguiendo experiencias propias que van conformando y dando forma a la ciudad (Hernández-García 2012). En el caso de los barrios populares, los usos dejan de lado la formalidad de la ciudad planeada y desarrollan actividades de diverso orden. Por ejemplo, un primer grupo de actividades de carácter más bien simbólico en el que se identifica la socialización, los acontecimientos de la comunidad, las manifestaciones tradicionales y las expresiones religiosas y políticas; un segundo grupo de interacciones concurrentes son las funcionales -movimiento (Carmona, Tiesdell, Heath y Oc 2003), descanso y relajación (Carr, Francis, Rivlin y Stone 1992) y encuentros sociales- que se traslapan en las prácticas diarias de las actividades opcionales y las rutinarias (Gehl 1999) y un tercer grupo de interacciones pueden ser las relacionadas con el poder y el conflicto (Low 2000; Rosenthal 2000) y explicadas por Madanipour $(1999,880)$ en los siguientes términos: "El control del espacio público es, por lo tanto, esencial en el equilibrio del poder en una sociedad particular". 
En este artículo se plantea que planeadas desde la formalidad (económica, política, técnica) o planeadas desde la informalidad (surgidas desde las prioridades, iniciativas y expectativas de la gente), las comunidades humanas usan, apropian y transforman su espacio vital y establecen relaciones de poder que se pueden observar en el control territorial y la apropiación del espacio que los diversos grupos tratan de ejercer sobre el espacio público y en el uso a veces beligerante de esos espacios.

Las interacciones relacionadas con el poder y el conflicto son consecuentes con todas las actividades que se desarrollan en los escenarios urbanos, ya sea en usos funcionales o simbólicos que la gente puede dar a los espacios públicos abiertos. Se ha de señalar que los escenarios en estudio en ambas investigaciones se denominan calle, parque, plaza o peatonal en tanto van respondiendo al discurso propio de los estudios urbanos, pero que dichos espacios se han construido y se imaginan diferente en cada caso. Los principales espacios públicos, que se definen en un manual para hacer ciudad diseñada como la que se exploró en San José, fueron el parque que aporta el verde de la ciudad, la plaza alegórica a un edificio histórico, la calle senda vehicular por oposición a la peatonal o senda para caminantes urbanos, todos espacios normados y predefinidos en usos e interacciones. En tanto, en el estudio en Bogotá, en el barrio popular, se construyen y configuran cotidianamente nuevas versiones de estos espacios para conformar nuevas y diferentes formas de usar, habitar y simbolizar los espacios para dar lugar igualmente a la calle, el parque y sus variantes. "Las calles pueden convertirse en escaleras, adaptándose a la topografía escarpada que encontramos en muchos barrios [de origen informal]" (Hernández García 2013, 149). "La calle principal del barrio es el lugar donde 'ocurre todo'. Es el lugar del transporte, las compras, los encuentros y el entretenimiento. Probablemente, en algún momento del día la mayoría de las personas llegarán a la calle principal por alguna razón: para tomar el autobús, comprar algo, encontrarse con alguien, o tomarse un par de cervezas con los amigos" (Hernández García 2013, 155). Las tradicionales plazas, plazoletas y parques arbolados han dado paso a la cancha, al parque de barrio, al espacio de juego, al espacio público con fines recreativos y deportivos; pero, a la vez, con valores sociales cotidianos y significado simbólico. La plaza se ha transformado en el parque de barrio, y la calle ha pasado de ser conector a ser el espacio social por excelencia; en ambos casos, mutando sus usos y apropiaciones tradicionales, pero con igual importancia en la construcción de subjetividades, de conflicto y de relaciones de poder.

Contraste de realidades, el gobierno local y los organismos de promoción de los denominados eventos culturales desarrollan manuales de visita para devolver a los espacios abiertos josefinos la vida que tuvieron en sus orígenes en tanto que en los barrios informales bogotanos recientemente se han intensificado los esfuerzos por medio de leyes e instituciones dirigidas a promover y regular la participación y uso de los espacios por parte de habitantes o visitantes. Sin embargo, las personas que los usan las que 
entretejen sus prácticas cotidianas y van conformando las verdaderas formas de habitar y usar esos espacios.

El presente artículo nace con la idea de poner a dialogar dos trabajos de investigación terminados. El primero de ellos atendió el tema del uso que le dan jóvenes estudiantes de secundaria a los espacios públicos en el centro de San José en tanto centro de ciudad diseñada que visitan cotidianamente. Se desarrolló en el 2006 como investigación de Maestría Académica en diseño urbano. Participaron 6 grupos de décimo año de instituciones de secundaria. En cada institución se desarrolló un taller en el que cada grupo se dividió para pensar, hablar y elaborar mapas. La consigna utilizada para los mapas fue conformar pequeños grupos y hacer un mapa representando los espacios públicos abiertos del centro de San José. Dicha consigna invitaba al recorrido imaginario por la ciudad. Además, contestaron un cuestionario individual y escribieron un texto breve de descripción del lugar preferido (Víquez, 2006). A propósito del presente artículo la zona de estudio se ha revisitado recientemente y se ha revisado nuevamente la información recolectada. El segundo estudio presentó el uso que le dan los habitantes de los barrios populares a sus espacios públicos en Bogotá. La investigación de Bogotá es de carácter longitudinal que arranca con los primeros registros en el año 2003. Del 2007al 2010 con la tesis doctoral del autor, se revisaron 56 casos de barrios populares de Bogotá. Se emplearon observación, mapeo y entrevistas a las personas que usan y actúan en los espacios públicos de los barrios: mujeres, hombres, niños, jóvenes, adultos y ancianos. A la fecha se han revisitado muchos casos y se han explorado unos nuevos. La presentación parte de los hallazgos de ambas investigaciones y el diálogo entre ellas y ha permitido identificar las potencialidades y los conflictos de estas dos maneras de "hacer ciudad" (a través de uso y la apropiación), mostrar la diversidad de nuestras ciudades latinoamericanas y discutir las relaciones de conflicto y de poder que se entretejen en el espacio público abierto.

\section{San José: ciudad con manual de usos para disfrute de la gente joven}

Kroneberg (1999) propone el estudio de la ciudad desde tres planos: la forma, la apariencia y la imagen de la ciudad. La forma corresponde a la ciudad existente; la apariencia es la ciudad efectiva y la imagen es la ciudad vivida. Se toma en consideración la memoria y la organización de los territorios psicológicos que se concreta en la representación y el significado. La ciudad vivida es la otra parte de la ciudad del observador-habitante. Se trata de la ciudad indagada por medio de los mapas mentales de Lynch.

La dimensión de la ciudad efectiva remite a las prácticas cotidianas guiadas por manuales de ciudad que invitan a jóvenes a incorporar a la ciudad en su vivencia cotidiana a visitar la plaza, el parque o la peatonal. Esta invitación se refiere con frecuencia a un programa recreativo de ciudad como un domingo 
sin humo en el que una de las vías principales de San José se transformaba en ciclovía y polideportivo, o ser parte de un desfile navideño de luces y fantasía. La ciudad imaginada surge, sin embargo, de entre los fragmentos de una ciudad efectiva propia del manual y se impone con lecturas propias y beligerantes que se mencionaban antes. Estas lecturas idiosincráticas renuncian a la ciudad de manual de actividades culturales y se enfrentan al conflicto. Esta dimensión aporta particularmente en el análisis de los espacios públicos abiertos, debido a que en ella se realiza lo que Kroneberg (2005) detalla como un proceso de lectura, de identificación de los elementos significativos, de evaluación del contexto a partir de lo relevante para los observadores y de definición de lo importante y lo accesorio e incluso lo desapercibido.

\section{Los mapas de los usos.}

Las personas jóvenes estudiantes que tomaron parte de la investigación en el centro de San José, que aquí se menciona, evidenciaron que los espacios públicos de la ciudad se usan para caminar, sentarse, "ver y ser visto" (Gehl, 2006), esperar el autobús, encontrarse con la pareja o los amigos, atravesar hacia otro punto de la capital, comprar una pulsera de artesanía, comer un helado, escuchar un artista callejero o simplemente caminar, "dar una vuelta por Chepe" . Mercado y tránsito -también algo de encuentro- son los usos primordiales. Los usos se refieren a la cercanía de la gente joven con los espacios inmediatos. La consigna les motivó a representarlos por medio de

1. Chepe es la forma coloquial muy común para referirse al centro de la ciudad de San José. dibujos, recortes de revistas o frases escritas cual grafitis de aquella ciudad vivida, percibida e imaginada plasmada en papel; lo que generó una elaboración abundante y diversa con cada uno de los 80 mapas resultantes.

\section{Ciudades superpuestas a pesar de los manuales.}

Los mapas plasmaron recorridos que hacen pensar en la experiencia de quien camina y se adueña del espacio, aunque sea por un momento, lo suficiente para conocerlo y diferenciarlo en su estética, su uso y sus horarios; sus bondades y sus decadencias. La experiencia primera dio paso a lo vivenciado a partir de ese espacio, representado en lo gráfico y en los textos de los mapas, en los recortes de revistas que escogieron y en las frases que escribieron. El plano de la imagen de San José, plasmada en este caso por medio de mapas colectivamente elaborados, fue escenario de las percepciones y las representaciones del arte urbano, de la luz, del color y de la imagen.

Abordando la tarea de dibujar el mapa a partir de las normas del trazado de ciudad (parque..., plaza..., peatonal...) se fueron presentando las aceras, las 
bancas, las calles, los elementos distintivos para dar paso poco a poco a las imágenes resultado de la experiencia y la vivencia.

Así, la ciudad fue dando origen a diferentes planos, algunos más cercanos y propios que otros. Por ejemplo, el Paseo Colón y la Avenida Segunda, por su uso, se constituyeron en la ciudad de los automóviles. Ambas vías juntas atraviesan el pequeño centro de oeste a este y son representadas en los mapas como un borde negro o como una doble fila de pequeños automóviles, que constituyen un eje dividiendo en dos el centro. Es una senda de vehículos que nada ofrece a los caminantes o a lo sumo se puede presagiar un atropello que se dibuja con cierta intemperancia.

La plana de la ciudad también trazó el parque Braulio Carrillo o Parque de La Merced como mejor lo conocen las personas que lo visitan y lo usan. Es el parque de los nicaragüenses. Nadie debería ser ilegal en la ciudad de manual; sin embargo, el parque de los inmigrantes se instaura como ciudad ilegal, representación cruel del desconocimiento del otro que surge en el paisaje urbano y lo usa como lugar de encuentro, intercambio y colaboración. Es una de las representaciones que evidencia conflicto entre la ciudad que se pretende igual y accesible y la que imaginan quienes la recorren. Es la experiencia de la presencia de migrantes que se vive cotidianamente en nuestras ciudades y que, sin embargo, en el caso de San José, fue representada en un mapa con el mote de "ilegales".

El recorrido imaginario plasmado en los mapas continúa hacia el este, pasando la Plaza de la Cultura y arremete al mapa un "me encanta" escrito de forma particular, ubicado al borde de la plaza que ostenta tal nombre. Como ironía para la investigadora, el referente principal para representar la plaza de la Cultura no es el Teatro Nacional -como habría preferido- sino un restaurante de la comida rápida que está al costado norte. La ciudad comercial, reflejo de las marcas y las modas, fue la principal inspiración. Al mirar hacia el sur, apenas a dos cuadras de la Plaza de la Cultura, la ciudad es de nuevo escenario de conflicto, se cambia de nombre. La representación ya no es la acoplada ciudad de la comida rápida sino que se convierte en la ciudad del miedo, del rechazo de los sectores peligrosos que no se deben visitar. La marcha continuó hasta la Plaza de las Garantías Sociales, de los romances estudiantiles y las paradas de buses, escenario de la reunión de muchachas y muchachos de los colegios vecinos que permite algo de control juvenil en ese espacio.

En el recorrido la ciudad fue cambiando de usuarios y el juego de fuerzas se transformó. De la apariencia a la imagen, tomaron el escenario los otros: indigentes, explotación sexual comercial de menores y mendicidad, evidencias de exclusión negadas durante el día que aparecen con frecuencia, sobre todo por la noche. Esa es la ciudad injusta, en la que el parque no se dibujó verde y con fuentes. En su lugar el parque se representó con frases escritas directamente en el mapa, a manera de grafiti que denuncian otra ciudad que no se ve o que se oculta pero que existe y en la que el conflicto no solo se presume sino que se visibiliza. Esta es la tercera 
escena del conflicto. Una vez más evidencia que la ciudad que invita a visitarla sin embargo también expulsa a los visitantes.

\section{Los espacios de la ciudad popular en Bogotá y la construcción de relaciones sociales, económicas y políticas}

Por otra parte el uso del espacio público en los barrios populares tiene que ver con las prácticas cotidianas de sus habitantes, tales como caminar, detenerse y encontrarse con el otro. El espacio público se va desarrollando desde la lógica del diario vivir, no desde lo planeado ni regulado en este sentido, se puede decir que el espacio se construye desde la informalidad. Las actividades básicas construyen otras, se desarrollan relaciones sociales, se expresan tradiciones y creencias individuales y colectivas, se desarrollan ideas y se forjan intereses políticos. Estas, sin embargo, se correlacionan con los usos más funcionales de los espacios públicos, tales como las actividades económicas y recreativas; todas ellas contribuyen a la construcción de significados experienciales y simbólicos. Como Rapoport $(1977,323)$ afirma con respecto a los espacios públicos: "Tienen mucho que ver con los individuos y los grupos. Se convierten en símbolos de identidad social, étnica y demás, y desempeñan un papel importante en la supervivencia de tales grupos". En esta construcción de identidades se crean sinergias, también conflictos, que evidencian las relaciones de poder que se tejen entre los distintos actores del espacio público.

\section{El espacio público como lugar de juego y comercio.}

Entre las actividades desarrolladas en el espacio público en los barrios populares, la más visible es la recreación activa que también se puede ver como una actividad social y cultural. En los barrios, espacio público y zona de juego son sinónimos, lo cual refuerza los argumentos de Beardsley y Werthmann (2008). Las calles son el espacio de juego primario y más asequible para los niños del barrio, puesto que la casa es limitada en términos de espacio y oportunidades sociales, los niños prefieren estar en la calle con sus amigos. "Los niños más pequeños juegan fútbol, montan bicicleta o sacan sus juguetes a la calle; en la mayoría de los casos, quienes cuidan de ellos son sus hermanos mayores o la gallada a la cual pertenecen" (Rojas y Guerrero 1997, 23).

En términos funcionales, los parques del barrio están destinados al juego y los deportes (Hernández-García 2012). Usualmente, tienen canchas multifuncionales para jugar básquet, microfútbol o volibol y varias zonas de juegos con estructuras metálicas o de madera. El resto del parque está pavimentado o tiene zonas verdes también adecuadas para jugar. 
El juego es, entonces, el vehículo no solamente para el uso y la apropiación del espacio público en los barrios populares, sino también el motivador principal en las construcciones sociales y simbólicas que allí se dan. Pero, tanto el uso como su significado no solo generan apropiación sino también producen conflicto, desde quien usa los espacios y quien no, a quien le molesta el ruido del juego o una pelota que se sale de la cancha, hasta territorialidades asociadas a bandas y grupos que pretenden ejercer su dominio.

\section{Relaciones de poder y conflicto.}

Se podría afirmar que la mayoría de los barrios populares comienzan su vida de manera conflictiva, mediante la ocupación ilegal del suelo y gradualmente se van convirtiendo en una parte integral de la ciudad y, por lo tanto, tienen poder de negociación. Kilian (1998) sostiene que estas restricciones de uso se pueden entender como relaciones de poder y que estas relaciones son particularmente importantes en los espacios públicos. El autor afirma que en los espacios públicos urbanos hay tres categorías de usuarios: los habitantes, los visitantes y los foráneos y que el conflicto obedece a las dinámicas de inclusión-exclusión entre estos grupos.

En los barrios populares, estos grupos se identifican así: el primero, los usuarios directos o la gente que vive alrededor del espacio público; el segundo, la gente del barrio o las zonas cercanas que utilizan el espacio público y el tercero, la gente que viene de otra parte (como generalmente sucede) que quiere tener el control del espacio por una razón particular. Este grupo puede incluir jóvenes que han sido rechazados y excluidos de otros espacios y que buscan uno 'propio'. Hay un cuarto grupo representado por las autoridades locales y los representantes de la comunidad como la Junta de Acción Comunal (JAC). Los conflictos motivados por una visión distinta del uso de los espacios públicos ocurren entre grupos y al interior de los mismos. En los barrios populares las dos causas principales de conflicto por el uso del espacio público son la que tiene se relaciona con el ejercicio de unos derechos sobre el territorio, relacionados con el acceso, el control y la seguridad; la otra se relaciona con el uso cotidiano del espacio (HernándezGarcía 2012).

Como en toda la ciudad, el espacio público en el barrio popular es el agente y, a la vez, el resultado de la construcción social de los grupos humanos. Esta construcción social se alimenta de la interacción de los distintos actores sobre el territorio y el cruce de sus agendas y sus objetivos; de esta manera, se construye la civilidad, también los conflictos y las relaciones de poder subyacentes. El espacio público en el barrio popular no es un espacio neutro, representa un espacio en conflicto por el uso, la apropiación y el significado. 


\section{Recapitulación y conclusiones}

Ambos estudios plantean relaciones de uso y apropiación del espacio de acuerdo con lógicas distintas a cómo fueron planeados (San José) o cómo la formalidad supone deben ser usados (Bogotá), que evidencian las relaciones entre los distintos actores y con la institucionalidad ya sea la municipalidad o el gobierno central al plantear situaciones de conflicto que reflejan a la vez relaciones de poder.

La lectura, más allá del manual y de los elementos estéticos, dio como resultado la identificación de varios planos de ciudad en los que la xenofobia, la saturación vehicular, la denuncia por la injusticia contra mujeres y niños en prostitución y la aglomeración de delitos conformaron mapas de ciudad ilegal, ciudad insegura y ciudad injusta; al tiempo que se superponen la ciudad de la moda y la ciudad de la estética.

En la ciudad popular el uso del espacio público está atado a las prácticas cotidianas y a la autogestión y autodesarrollo del espacio; muchas veces en contravía de la norma jurídica y urbanística, o simplemente en ausencia de ellas. El espacio público en el barrio popular tan solo se usa más allá de perspectivas normativas, jurídicas o políticas. Es allí donde nace el conflicto, donde lo formal dicta cómo debe ser el espacio pero no brinda oportunidades para desarrollarlo y si las brinda no son necesariamente lo que la gente necesita. Dicho conflicto esconde, en muchos casos, intereses particulares. Muchos de ellos de orden político y de lucha de poderes.

Se ha querido compartir hasta ahora que, con abordajes distintos, ambas investigaciones han llegado a conocer el uso de los espacios desde quienes los habitan y no desde lo que se señala en las normas. Los mapas del centro de San José resultaron diversos y, a la vez, fragmentados y son en realidad el resultado de la superposición de distintos imaginarios (García Canclini 1997) de la ciudad que ya va de vuelta, buscando rescatar el plano de la imagen con cara cotidiana, pero que no escapa al conflicto cotidiano que se escenifica en ella. En tanto, la ciudad rescatada en sus crónicas de las prácticas cotidianas evidencia que los espacios se construyen a partir de su cara cotidiana no por ello exenta de conflicto sino gracias a este. En ambos casos se integran diferentes planos en un solo territorio, al que cada grupo le dio connotaciones distintas, según sus propias preocupaciones.

La imagen evocada de la ciudad limpia reúne las percepciones de los distintos planos en una sola en la que confluyen las características del territorio que es lavado cada día por los benéficos aguaceros que se encargan de dejarle la cara lavada para iniciar el día. Característica, además, que evoca una mezcla de imágenes olfativas y visuales más propias de un espacio natural que queda limpio después del aguacero. De alguna manera, se asocia al espacio construido por medio de valoraciones acerca de lo bueno como la limpieza versus lo sucio como el uso no querido, como el exceso de vehículos y la gente que vive en edificios insalubres y que "ensucia" la ciudad cuando sale. Esta imagen es, además, una llamada de atención de parte de este grupo que vive todos los días el centro de la ciudad 
y cuya preocupación denuncia un problema que va más allá de un análisis de espacios públicos y que tiene que ver con las condiciones de vida de algunos de los actuales habitantes de San José. Por otra parte, en Bogotá, las actividades sociales, económicas y políticas cotidianas que se desarrollan en los espacios públicos contribuyen a darle forma a estos lugares desde lo socio-espacial. Las relaciones se construyen en las calles y los parques; sus esquinas y fronteras adquieren 'nuevos' usos y la transformación del espacio se va dando desde cada pequeña intervención que acomoda usos y apropiaciones necesarias o esperadas desde una nueva planta que se siembra hasta un kiosko que se construye para albergar reuniones de la comunidad. Pero, estas actividades sociales y espaciales también ayudan a construir una red de conexiones con el lugar, como Carr, Francis, Rivlin y Stone $(1992,193)$ sostienen: "Asumiendo que existe un cierto grado de relevancia o de congruencia entre los lugares y sus usuarios, el uso puede crear conexiones simbólicas".

Como señala Madanipour (1999, 880): "El control del espacio público es por lo tanto esencial en el equilibrio del poder en una sociedad particular". En los barrios, el gobierno local es en teoría uno de los reguladores de este espacio mediante las leyes y normas vigentes en la ciudad en su totalidad; pero en términos prácticos, los usuarios habituales en San José o la comunidad de los barrios informales de Bogotá son quienes organizan los códigos de uso y trata de hacerlos funcionar. A este respecto, Lawson (citado en Carmona, Tiesdell, Heath y Oc 2003, 108) "afirma que los individuos que habitan colectivamente un área tienden a establecer 'reglas' para su uso del espacio [...], [aunque] algunas de ellas son una convención social y cultural local".

Respecto de esto, el artículo también ha podido identificar los conflictos que se generan en los espacios a partir de quienes los habitan desde antes y quienes llegan luego a hacer uso de él. Migrantes o comunidades recién constituidas trasgreden las reglas de uso de los usuarios o habitantes originarios del espacio público definida por Kilian (1998).

Tanto en San José como en Bogotá afloran los conflictos y se evidencian los juegos de poder que suscita y se suscitan en el espacio público. En ambos casos, los espacios públicos están enmarcados en contextos de normativa institucional, historia de la planificación a la vez que subyacen lógicas distintas de uso y apropiación del espacio, que nos permite encontrar diferencias y semejanzas en estas dimensiones, dadas por la confluencia en ambos casos de espacios no tanto diseñados sino vividos en la ciudad, que evidencian también las relaciones conflictivas y de poder en el espacio público entre los distintos actores que se relacionan con el espacio incluyendo la institucionalidad.

La investigación con jóvenes en la ciudad de San José permite presentar la relación que establecen con el espacio público que se muestra como escenario de ciudad referenciada por los hitos urbanos, los usos y las prácticas sociales de quienes van de paso o se sienten interpelados a visitar esos espacios y se sorprenden. En contraposición, existe otro tipo de vivencia. Es la vivencia del habitante urbano que crea un asentamiento y se 
ve en la obligación de ajustarse a las normas de uso y prácticas que se construyen desde la cotidianidad, el conflicto y las relaciones de poder que se entretejen.

El diálogo entre estos usos y prácticas sociales en el espacio público en estos dos contextos permite explorar la riqueza y diversidad encontrada en estas dos ciudades, y permite identificar relaciones socio-espaciales de la informalidad y de la regulación al apuntar que ni una ni otra manera es óptima, pero tanto de una como de otra práctica se pueden extraer valiosos aprendizajes.

La informalidad es la gente tomando acción sobre su propio hábitat y siendo responsable del mismo (Hernández-García 2016) y la regulación es el Estado al colocar reglas de juego para mejorar la convivencia urbana. La informalidad genera conflictos, la regulación impone formas de actuar, a veces, contrarias a las expectativas de la gente y genera distancia y desarraigo. Sin embargo, tanto en la informalidad como en la regulación las relaciones de poder establecen la dinámica que se ve cotidianamente en los espacios, lo permitido y lo expulsado conviviendo en la ciudad (HernándezGarcía 2012; Víquez 2006).

\section{Referencias}

Beardsley, J. y C. Werthmann. 2008. «Improving Informal Settlements: Ideas from Latin America». Harvard Desing Magazine, 28: 31-35.

Carmona, M., Steve Tiesdell, Tim Heath y Tanner Oc. 2003. Public Places, Urban Spaces. Oxford: Architectural Press.

Carr, Stephen. Mark Francis, Leanne G. Rivlin y Andrew M. Stone. 1992. Public Space. Cambridge: Cambridge University Press.

Carrión, F. 2007. «Espacio Público: Punto de Partida para la Alteridad». En Espacios públicos y construcción social. Hacia un ejercicio de ciudadanía, editado por O Segovia Santiago de Chile: Ediciones SUR, 79-97.

García Canclini, E. 1997. Imaginarios Urbanos. Argentina: Editorial Universitaria de Buenos Aires.

Gehl, J. 1999. «Apuntes del Curso Especial de Posgrado Vida entre edificios y espacios públicos». Universidad de Costa Rica. Maestría en Diseño Urbano. Escuela de Arquitectura. 
Gehl, J. 2005. «Apuntes del Seminario La humanización del espacio urbano. Universidad de Costa Rica». Maestría en Diseño Urbano. Escuela de Arquitectura.

Harvey, D. 2013 Ciudades Rebeldes. Del derecho a la ciudad a la revolución urbana. Madrid: Akal.

Hernández García, Jaime. 2016. «Sustainability Citizenship: Lessons and Challenges from Informal Settlements». En Sustainability Citizenship, editado por Horne, R., Fien, J., Beza, B.B., y Nelson, Anitra.. Australia: Routedge, 129-138.

Hernández García, Jaime. 2013. «Construcción Social de Espacio Público en Barrios Populares de Bogotá». Revista INVI, 78(28).

Hernández-García, Jaime. 2012. Espacios Públicos en Barrios Informales. Producción y Uso entre lo Público y lo Privado. México: INFONAVIT y REDALYC.

Kilian, T. 1998. «Public and Private, Power and Space». En The Production of Public Space, compiladores Light, A y Smith, J. Philosophy and Geography II. Oxford: Rowman and Littlefield, 115-134.

Kroneberg, I. 1999. «Apuntes del Curso Especial de Posgrado: Planificación de la imagen urbana». Maestría en Diseño Urbano, Universidad de Costa Rica. Escuela de Arquitectura.

Kroneberg, I. 2005. «Apuntes del seminario: Planificación de la imagen urbana». Maestría en Diseño Urbano, Universidad de Costa Rica. Escuela de Arquitectura.

Low, S. 2000. On the Plaza, The Politics of Public Space and Culture. Austin: University of Texas Press.

Rapoport, A. 1977. Aspectos humanos de la forma urbana. España: Editorial Gili.

Madanipour, A. 1999. «Why are the Design and Development of Public Spaces Significant for Cities? Environment and Planning B» Planning and Design, 26: 879 - 891. 
Rojas, E. y M. Guerrero. 1997. «La Calle del Barrio Popular: Fragmento de una Ciudad Fragmentada. Barrio Taller». Serie Ciudad y Habitat, 4: 140.

Rosenthal, A. 2000. «Spectacle, Fear and Protest. A Guide to the History of Urban Public Space in Latin America». Social Science History, 24(1): 34-73.

Víquez, R. 2006. Los jóvenes y los espacios públicos abiertos. Algunas consideraciones para el diseño urbano. Tesis para optar al grado de Magíister Scientae en Diseño Urbano. Escuela de Arquitectura. Universidad de Costa Rica.

Víquez, Rosibel y Mauricio Leandro. 2006. «Espacios públicos y percepción de los adolescentes urbanos». Revista Reflexiones, 85(1). 